\title{
Codesign of the Population Health Information Management System to measure reach and practice change of childhood obesity programs
}

\author{
Amanda M Green, ${ }^{a, i}$ Christine Innes-Hughes ${ }^{a}$, Chris Rissela,b, Jo Mitchellc, \\ Andrew J Milatt,d, Mandy Williams ${ }^{\mathrm{e}}$, Lina Persson ${ }^{\mathrm{d}}$, Sarah Thackway ${ }^{\mathrm{d}, \mathrm{f}}$, \\ Nicola Lewis ${ }^{c}$ and John Wiggersg,h
}

a NSW Office of Preventive Health, NSW Ministry of Health, Sydney, Australia

b Sydney Medical School, University of Sydney, NSW, Australia

c Centre for Population Health, NSW Ministry of Health, Sydney, Australia

${ }^{d}$ Centre for Epidemiology and Evidence, NSW Ministry of Health, Sydney, Australia

e South Western Sydney Local Health District, NSW, Australia

f School of Public Health and Community Medicine, UNSW Sydney, Australia

g Hunter New England Local Health District, Newcastle, NSW, Australia

n School of Medicine and Public Health, University of Newcastle, NSW, Australia

Corresponding author: Amanda.Green@health.nsw.gov.au

\section{Article history}

Publication date: September 2018

Citation: Green AM, Innes-Hughes C, Rissel C, Mitchell J, Milat AJ, Williams M, Persson L, Thackway S, Lewis N, Wiggers J. Codesign of the Population Health Information Management System to measure reach and practice change of childhood obesity programs. Public Health Res Pract. 2018;28(3):e2831822. https://doi.org/10.17061/phrp2831822

\section{Key points}

- The Population Health Information Management System (PHIMS) has delivered an innovative information technology solution to support performance monitoring and reporting of key childhood obesity prevention programs delivered at scale across New South Wales, Australia

- PHIMS has provided an opportunity for health promotion initiatives and staff to have a 'seat at the table' with agents of authority through the use of PHIMS data for monitoring performance

\begin{abstract}
Introduction: Childhood obesity prevalence is an issue of international public health concern and governments have a significant role to play in its reduction. The Healthy Children Initiative $(\mathrm{HCl})$ has been delivered in New South Wales (NSW), Australia, since 2011 to support implementation of childhood obesity prevention programs at scale. Consequently, a system to support local implementation and data collection, analysis and reporting at local and state levels was necessary. The Population Health Information Management System (PHIMS) was developed to meet this need.
\end{abstract}

Design and development: A collaborative and iterative process was applied to the design and development of the system. The process comprised identifying technical requirements, building system infrastructure, delivering training, deploying the system and implementing quality measures.

Use of PHIMS: Implementation of PHIMS resulted in rapid data retrieval and reporting against agreed performance measures for the $\mathrm{HCl}$. The system has 150 users who account for the monitoring and reporting of more than $6000 \mathrm{HCl}$ intervention sites (early childhood services and primary schools).

Lessons learnt: Developing and implementing PHIMS presented a number of complexities including: applying an information technology (IT) development methodology to a traditional health promotion setting; data access and confidentiality issues; and managing system development and deployment to intended timelines and budget. PHIMS was successfully codesigned as a flexible, scalable and sustainable IT solution that supports state-wide $\mathrm{HCl}$ program implementation, monitoring and reporting. 


\section{Introduction}

Childhood overweight and obesity is of international public health concern and governments have a significant role to play in addressing the issue. ${ }^{1}$ In New South Wales (NSW), Australia, the prevalence of childhood overweight and obesity remains high, at $21 \%$. $^{2}$

From 2011 to 2014, the Australian Government implemented the National Partnership Agreement on Preventive Health, which provided an historic increase in funding to prevent chronic disease. In NSW, this coordinated prevention effort for children was delivered through the Healthy Children Initiative $(\mathrm{HCl})$ by the NSW Ministry of Health (the Ministry). The $\mathrm{HCl}$ involves the implementation of primary and secondary obesity prevention programs across the state in settings attended by children, for example, early childhood services and primary schools. ${ }^{3}$

A well-established health promotion workforce existed in NSW that had designed and implemented programs in these settings and had the potential to achieve statewide population-level reach and outcomes. However, a significant scaling up of delivery and monitoring of these programs was required to effect population-level change. To facilitate this, enhanced funding was provided to all 15 NSW Government Local Health District (LHD) health promotion services to support local implementation of these programs. ${ }^{4}$

Two programs, Munch \& Move and Live Life Well @ School(LLW@S), were identified from pilot programs to be delivered at scale across NSW as part of the $\mathrm{HCl}$. Munch \& Move had a potential reach of more than 3500 centre-based early childhood services and more than 190000 children aged 0-5 years. LLW@S had a potential reach of more than 2400 primary schools with more than 675000 students.

Initial implementation of both Munch \& Move and LLW@S involved training of educators and teachers to embed the promotion of healthy behaviours in their organisational policy and routine practice. To ensure the successful translation into routine practice, educators and teachers were supported by their local LHD through regular visits or phone calls, and they were monitored through a set of program adoption indicators referred to as 'practices'. These evidence based practices refer to organisational policies and practices related to nutrition, physical activity and sedentary behaviour (see Tables 1 and 2). ${ }^{5,6}$

Table 1. Munch \& Move practices

$\begin{array}{ll}\text { Encouraging } & \text { Lunchboxes monitored daily } \\ \text { healthy eating } & \text { Fruit and vegetables at least once per day } \\ & \text { Only healthy snacks on the menu } \\ & \text { Water or age-appropriate drinks every day } \\ & \text { Healthy eating learning experiences at } \\ & \text { least twice per week } \\ \text { Daily physical } & \text { Tummy time for babies every day } \\ \text { activity } & \text { Physical activity for at least 25\% of opening } \\ & \text { hours (ages 1-5 years) } \\ & \text { Fundamental movement skills every day } \\ \text { (ages 3-5 years) } & \text { Appropriate use of small-screen recreation } \\ \text { (ages 3-5 years) } & \text { Written nutrition policy } \\ \text { Policies in place } & \text { Written physical activity policy } \\ & \text { Written policy restricting small-screen } \\ \text { recreation }\end{array}$

Table 2. Live Life Well @ School (LLW@S) practices

Curriculum

Encouraging healthy eating and physical activity

Professional development and monitoring
Healthy eating and physical activity learning experiences

Personal development, health and physical education includes fundamental movement skills

Fruit, vegetables and water breaks

Physical activity during breaks

Supportive environment for healthy eating Communication with families

Professional development of staff

School team supports LLW@S

School plans incorporate LLW@S strategies

Annual monitoring and reporting 
Consistent with World Health Organization recommendations, a comprehensive $\mathrm{HCl}$ monitoring framework was developed to guide the review of program implementation in early childhood services and primary schools. This framework was operationalised by including $\mathrm{HCl}$ measures in the annual service agreements between the Ministry (the funder) and LHDs (the providers). Achievement against the measure was reviewed quarterly.

Contemporary and effective delivery of populationlevel health interventions requires innovative technology and fresh approaches to monitoring and reporting. Conte et al. ${ }^{7}$ described the lack of evidence about whether an e-monitoring system improved the implementation of evidence based preventive programs. However, because performance measures were included in the LHD service agreements, a system was needed to support the implementation of the $\mathrm{HCl}$ at the local level, and the collection, recording, analysis and reporting of this data at both local and state levels. To achieve this, an information technology (IT) system called the Population Health Information Management System (PHIMS) was developed to perform these functions for both LHD and Ministry staff.

\section{Design and development}

\section{Governance}

In July 2011, a Project Board was formed with representatives from each of the project stakeholder groups across the Ministry and LHDs. The purpose of the Board was to facilitate collaboration and guide the development of an overarching performance monitoring framework. A dedicated business analyst was engaged to consult with future users and to develop the business requirements document.

\section{Development process}

Codesign was undertaken between the Ministry and LHDs, who contributed to the development of the business requirements and monitored the implementation of the new system. A third-party vendor was contracted to undertake the build, user acceptance testing and deployment support.

Development involved an iterative process. The system's dual purposes (local and state-level application) were first clarified, with subsequent identification of related needs and operational priorities to be included in the business requirements document. This was completed in May 2012 and used by the solution architect and system developers to guide the design of the functional architecture. A commercial 'off-theshelf solution' was adapted to build a 'fit-for-purpose' system that met the needs of stakeholders and could be integrated into an existing organisational system.
User acceptance testing, training of LHD staff and deployment followed, with the system going live in August 2014. Project initiation to deployment took just over 3 years; the stages of development are depicted in Figure 1.

\section{Technical requirements and specifications}

The business analysis stage of the project identified two key requirements of the system: to support local delivery of $\mathrm{HCl}$ programs across NSW by providing contact management and scheduling capabilities for health promotion officers (HPOs); and to support the Ministry performance management framework. ${ }^{8}$

The system uses a Windows-based application that uses Microsoft Dynamics Customer Relationship Management (CRM), Select Survey (questionnaire component), SSRS (SQL Server Reporting Services) for reporting, and a state-wide login service.

\section{User acceptance testing}

User input and feedback was obtained from state-level program managers and through demonstration visits with LHD health promotion services. This ensured user needs were met and questions about the new system were addressed.

\section{Training and deployment}

Deployment of PHIMS was supported by representatives from each of the 15 LHDs (referred to as 'champions') and 11 staff within the Ministry. The business analyst conducted a 2-day training course with the LHD champions and Ministry staff. Then, prior to system deployment, webinar training was conducted for each LHD, consisting of 40 1-2-hour sessions with approximately 100 attendees. A set of tip sheets was also developed.

The system was deployed in six stages from August 2014 , starting with a pilot in one LHD and subsequent sequential roll-out to the remaining 14 LHDs, completed in September 2014.

Data cleaning and migration took more than 12 months, running in parallel with the build, user acceptance testing and deployment stages. Identifying and addressing data migration issues was a key factor in the successful deployment of PHIMS. Various interim data systems were in place in LHDs and needed to be integrated during the data migration process. Most issues were noncritical and occurred after data migration or within the first 3 months after deployment. Most of the system issues $(550 / 566,97 \%)$ had been resolved within 12 months of deployment. 
Figure 1. Timeline GANTT chart

\begin{tabular}{|c|c|c|c|c|c|c|c|c|c|c|c|c|c|c|c|c|}
\hline & $\begin{array}{l}\overline{5} \\
\frac{2}{2} \\
\frac{3}{3}\end{array}$ & $\begin{array}{l}\overline{0} \\
\frac{0}{0} \\
\frac{0}{0} \\
0 \\
\overline{2}\end{array}$ & 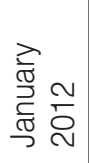 & $\begin{array}{l}\stackrel{N}{\sigma} \\
\stackrel{\sim}{\pi} \\
\frac{\pi}{2}\end{array}$ & $\begin{array}{l}\frac{N}{2} \\
\frac{N}{3} \\
\frac{3}{3}\end{array}$ & $\begin{array}{l}\overline{\bar{d}} \\
\frac{0}{0} \\
\frac{0}{0} \\
0 \\
0\end{array}$ & 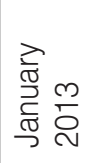 & 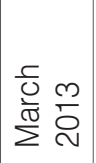 & $\begin{array}{l}\frac{m}{2} \\
\stackrel{2}{3} \\
\frac{3}{3}\end{array}$ & 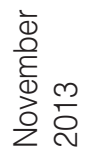 & 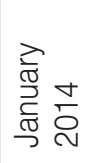 & 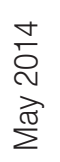 & 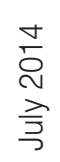 & 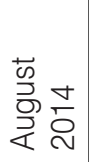 & 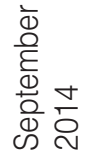 & 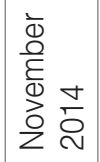 \\
\hline Project initiation & & & & & & & & & & & & & & & & \\
\hline Business analysis & & & & & & & & & & & & & & & & \\
\hline $\begin{array}{l}\text { Procurement } \\
\text { process }\end{array}$ & & & & & & & & & & & & & & & & \\
\hline $\begin{array}{l}\text { Detailed system } \\
\text { design }\end{array}$ & & & & & & & & & & & & & & & & \\
\hline System build & & & & & & & & & & & & & & & & \\
\hline $\begin{array}{l}\text { Data cleaning and } \\
\text { migration }\end{array}$ & & & & & & & & & & & & & & & & \\
\hline $\begin{array}{l}\text { User acceptance } \\
\text { testing }\end{array}$ & & & & & & & & & & & & & & & & \\
\hline Pilot LHD go-live & & & & & & & & & & & & & & & & \\
\hline Deployment & & & & & & & & & & & & & & & & \\
\hline
\end{tabular}

LHD = Local Health District

\section{User interface and reporting}

The user views a dashboard screen that contains a bulletin board for system announcements, website links and real-time program adoption graphs for the Munch \& Move and LLW@S programs. The system is made up of a hierarchy of forms (windows) that present information and enable the user to perform various actions.

PHIMS has the following key features that are used by $\mathrm{HPOs}$ to support local implementation of $\mathrm{HCl}$ programs:

1. Contact management: supports HPO workflows for managing interactions with sites (i.e. early childhood services and primary schools) and allows the user to record details in the one location. This has improved record keeping and retrieval and is a well-used function of the system with more than 54000 entries.

2. Capacity to record each site's training: demonstrates program reach (i.e. sites formally trained in Munch \& Move or LLW@S).

3. Scheduled follow-up alerts and recording of program adoption: alerts an HPO to when a site visit is due at 1-, 6- and 12-month intervals. During the visit, the HPO collects data on the program practices and enters it into the scheduled follow-up summary form (which links to the questionnaire [Select Survey] component). This data is then used for the performance monitoring reports. Other details from the visits are captured in the contact notes.
4. Operational reporting: allows HPOs to see which sites need additional support. Examples of reports are summaries of training entries, scheduled follow-ups, practice achievement and program adoption over time.

PHIMS has the capability to support reporting at state level by monitoring program reach (e.g. number of sites trained), practice achievement and program adoption.

The reports are generated in real time and allow the user to search and display data by specific criteria, for example, NSW, LHD or local government area, or sites in disadvantaged areas.

\section{Use of PHIMS}

\section{System analytics}

The system currently has 150 users across the 15 LHDs and the Ministry. They represent the workforce in each LHD and all state-level program and performance monitoring staff, and collectively are responsible for the monitoring and reporting of more than 6000 sites.

Educators and teachers have attended more than 24000 training events (i.e. workshops, conferences, webinars).

There are 70 reports available for day-to-day operational use by LHDs and to monitor performance by the Ministry. 


\section{Monitoring data}

PHIMS has provided a mechanism for reporting changes in program implementation in targeted children's settings over time. Box 1 describes the reach and adoption of the Munch \& Move and LLW@S programs.

Box 1. Example of how PHIMS data can be used for program monitoring and reporting

From 2008 to June 2015, 89\% (3288/3691) of early childhood services across NSW participated in Munch \& Move training. Since state-wide monitoring started in 2012, there has been steady growth in the number of early childhood services that have adopted Munch \& Move. Adoption of the program is reported with reference to the number of services achieving $70 \%$ (or more) of the practices that are relevant for that particular service. There has been a statistically significant increase in the proportion of early childhood services that have adopted the program. In 2012, the total for NSW was $36 \%$ and, by 2015 , this increased to $78 \%$ $(p<0.001){ }^{5}$

From 2008 to June 2015, 84\% (2039/2440) of primary schools across NSW participated in LLW@S training. The proportion of trained primary schools that have achieved the practices has significantly increased from $32 \%$ in 2012 to $77 \%$ in $2015(p<0.001)$.

PHIMS has delivered an innovative IT solution ${ }^{9}$ in a health promotion setting. Engaging in a best-practice 'agile'10 and collaborative development process was a significant contributor to the effectiveness and high uptake of the system.

\section{Challenges}

There were several complexities experienced in developing and implementing PHIMS. For example, LHDs requested confidentiality around operational data. Developing data governance and reporting protocols in response to the various needs of stakeholders was a key feature.

The decision to modify an off-the-shelf solution offered a value-for-money, sustainable and flexible final product. The final centralised cost was close to AU\$1 million.

Negotiating the local and state health IT environments to support important functionality in differing operating environments and to achieve single sign-on was a major undertaking.

\section{Benefits}

PHIMS appears to have multiple benefits. These include the ability to rapidly retrieve data for both operational and monitoring purposes. This has revolutionised the implementation of the $\mathrm{HCl}$ programs and is an important factor in the high degree of user acceptance and uptake.
This high degree of acceptability contributes to the sustainability of the system.

Importantly, PHIMS has provided an opportunity for health promotion initiatives and staff to have a 'seat at the table' with agents of authority (such as LHD chief executives and performance management executives) by providing real-time data on progress against performance measures. PHIMS also provides valuable performance monitoring and feedback to those who directly implement the program.

\section{Conclusion}

PHIMS was successfully codesigned to be a flexible, scalable and sustainable IT solution that supports $\mathrm{HCl}$ program implementation and provides data for state-level monitoring and reporting against agreed LHD performance measures. PHIMS could potentially be expanded to include other health promotion programs such as food provision in health facilities and tobacco retailer compliance.

\section{Acknowledgements}

We acknowledge the contributions of Liz King, Neil Orr, Louise Farrell, Bev Lloyd, Andy Bravo, Masela Draper, Deni Fukunishi, Andy Lui, Rita Lagaluga, Evan Freeman, Elena Ouspenskaia, Claudine Lyons, Kym Buffett, Rhonda Matthews, Project Advisory Board Members, Steering Committee Members, Transition Group and Reference Group Members and the Directors and staff of Local Health District Health Promotion Services across NSW.

This paper was developed as part of a program of research on monitoring health promotion practice within The Australian Prevention Partnership Centre. It was funded through the National Health and Medical Research Council Partnership Centre Grants Scheme (ID GNT 9100001) with the Australian Government Department of Health, the NSW Ministry of Health, ACT Health and the HCF Research Foundation.

\section{Peer review and provenance}

Externally peer reviewed, commissioned.

\section{Competing interests}

None declared.

\section{Author contributions}

$\mathrm{AG}$ and $\mathrm{Cl}-\mathrm{H}$ drafted the manuscript. CR, JM, AM, MW, LP, ST, NL and JW reviewed and contributed to editing the manuscript. All authors read, revised and approved the final manuscript. All authors contributed to the development and/or implementation of PHIMS. 


\section{References}

1. World Health Organization. Report of the commission on ending childhood obesity. Geneva: WHO; 2016 [cited 2018 Feb 7]. Available from: apps.who.int/iris/bitstream/ handle/10665/204176/9789241510066_eng.pdf;jsessio nid=4EA7FECA778E7E3B8C7BA4420E1B2412?sequen $\mathrm{ce}=1$

2. Health Stats NSW. Sydney: NSW Health. Overweight and obesity in children aged 5 to 16 years, NSW 2007 to 2017. Sydney: NSW Ministry of Health; 2018 [cited $2018 \mathrm{Jul} 10$ ]; [about 1 screen]. Available from: www.healthstats.nsw.gov.au/Indicator/beh_bmikid_cat

3. Innes-Hughes C, Bravo A, Buffett K, Henderson L, Lockeridge A, Pimenta N, et al. NSW Healthy Children Initiative: the first five years July 2011 - June 2016. Sydney: NSW Ministry of Health; 2017 [cited 2018 Feb 8]. Available from: www.health.nsw.gov.au/heal/Publications/ $\mathrm{HCl}$-report.pdf

4. Commonwealth of Australia. Implementation Plan for the NSW Healthy Children Initiative. Canberra; Commonwealth of Australia; 2012 [cited 2018 Feb 8]. Available from: www.federalfinancialrelations.gov.au/ content/npa/health/_archive/healthy_workers/healthy_ children/NSW_IP_2013.pdf

5. Lockeridge A, Innes-Hughes C, O'Hara BJ, McGill B, Rissel C. Munch \& Move evidence and evaluation summary. Sydney: NSW Ministry of Health; 2015 [cited 2018 Feb 8]. Available from: www.health.nsw.gov.au/ heal/Publications/Munch-Move-Evaluation-Summary.pdf
6. Bravo A, Innes-Hughes C, O'Hara B, McGill B, Rissel C. Live Life Well @ School evidence and evaluation summary 2008-2015. Sydney: NSW Ministry of Health; 2016 [cited 2018 Feb 8]. Available from: www.health.nsw. gov.au/heal/Publications/LLW@S-report.pdf

7. Conte KP, Groen S, Loblay V, Green A, Milat A, Persson L, et al. Dynamics behind the scale up of evidence-based obesity prevention: protocol for a multi-site case study of an electronic implementation monitoring system in health promotion practice. Implementation Sci. 2017;12(1):146.

8. Farrell L, Lloyd B, Matthews R, Bravo A, Wiggers J, Rissel C. Applying a performance monitoring framework to increase reach and adoption of children's healthy eating and physical activity programs. Public Health Res Pract. 2014;25(1);e2511408.

9. Australian Information Industry Association Awards. Canberra: AllA. NSW iAwards winners \& merit recipients. Canberra: AllA; 2015 [cited 2018 Feb 8]. Available from: www.iawards.com.au/history/2015/winners/nsw

10. Beck K, Beedle M, Van Bennekum A, Cockburn A, Cunningham W, Fowler M, et al. Manifesto for agile software development. US: Agile Allegiance; 2001 [cited 2018 Feb 8]. Available from: agilemanifesto.org/

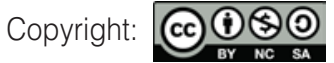

(c) 2018 Green et al. This article is licensed under the Creative Commons Attribution-NonCommercial-ShareAlike 4.0 International Licence, which allows others to redistribute, adapt and share this work non-commercially provided they attribute the work and any adapted version of it is distributed under the same Creative Commons licence terms. See: www.creativecommons.org/licenses/by-nc-sa/4.0/ 